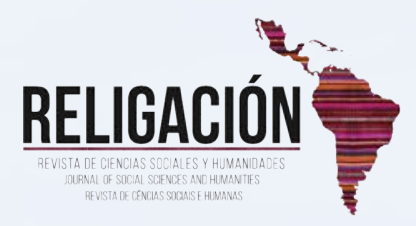

Fotoensayo

\title{
Paisaje fúnebre, Desvanecimiento del rito de ofrenda y proliferación de lo igual
}

\author{
Funeral landscape, Fading of the rite of offering and proliferation of the same
}

Camila Rodríguez Moraga | Universidad Católica del Maule - Chile |

Autora independiente, Chile. Socióloga de la Universidad Católica del Maule, Chile. E-mail: camilarodriguezmor@gmail.com

Con la masificación del plástico, el paisaje se modifica y así mismo las prácticas fúnebres, de modo que ya no es urgente recolectar, buscar o comprar flores naturales y frescas, si no, que, hoy en día las flores plásticas constituyen una estrategia real que funciona de forma sistemática contra el olvido, contra la precariedad, y para hacer frente a la naturaleza como es el caso de este cementerio ubicado en Balmaceda, pueblo patagónico del sur de Chile, azotado no solo por procesos de deterioro esperados por el paso de tiempo, si no, que, también por incendios y la propia naturaleza del clima que resulta avasalladora.

El consumo de estos objetos plásticos invisibiliza los fenómenos de aplazamiento y desidia en la "rendición de visitas" a los fallecidos provocada por múltiples variantes globalizantes. Sin embargo, esta manifestación también es consecuencia de aspectos socioespaciales locales como el desplazamiento de generaciones jóvenes y adultas hacia las grandes urbes regionales en busca de mejores condiciones económicas que generan un desvanecimiento del rito de visita y ofrenda floral; así como también de fenómenos transnacionales de producción y comercio a gran escala desatando por sobre todo una proliferación de lo igual y homogeneidad.

Las flores en Balmaceda duran mil años. Ya no hay tiempo para velar ni ofrendar al fallecido, la gente migra, los muertos se quedan, y quizás, después de tantos desalojos y despojos en Balmaceda, el cementerio es lo único que ha permanecido en su lugar durante tantos años. En estos terrenos yermos, pequeños y fronterizos, los poblados se desvanecen y si tienen suerte, pasan a la historia a duras penas con sencillas anécdotas locales. Sin embargo, las flores se quedan.

Estos objetos, hallan aquí su propia expresión de la representación de la vida, así como también de la vida contingente y globalizada. La flor plástica, constituye una estrategia comunicativa anti desvanecimiento; una solución y una simulación de la presencia de vida, que resulta ser una materialización de la propia inmortalidad, de la atención y cuidado familiar, de la negación de la muerte y el olvido, captando de igual forma, la naturaleza del capitalismo, otros regímenes, y la explotación humana que nos relaciona con otras latitudes. De esta forma, es como la propia población consumidora de flores baratas, exóticas y perdurables en el tiempo, de factura uniforme, transformará sus formas de culto local dejando expuesta la mercantilización que hay detrás y los procesos de producción a grandes lotes generados por trabajadores de bajo costo, alienados y explotados de bajo sueldo.

Los grandes paradigmas de producción masiva se experimentan aquí mediante esta actividad tan particular y colectiva que llamamos muerte. Todo el conjunto de procesos regulados como el funeral, los entierros, las tumba y lápidas; seguido de las ofrendas, velaciones, adornos, la limpieza, hasta incluso epitafios, repetidos una y otra vez, diferenciados escasamente por una o dos palabras persiguen la homogeneidad en la decoración nublando las particularidades de cada contexto. 
El paisaje fúnebre de Balmaceda en otros sentidos también se transforma: en el lugar donde tumbas, corrales, mausoleos y lápidas se constituían de ladrillo y madera, han sido permutados por materiales densos de larga duración como cemento y lata, y otros sencillos, resistentes al clima y al paso del tiempo como peñascos de rocas, ruedas y bolsas de plástico que hacen frente a la naturaleza hostil, demarcando las simples coordenadas, haciendo frente al abandono de los muertos con lo que se tiene a mano. Por ello, la reja que circunda el perímetro a pesar de no ser funcional representa una solución de contención o resistencia hacia la naturaleza avasalladora y mancomunar al igual que la hojalata, el vidrio, el cemento y las flores plásticas en este acto de defensa hacia el clima y el viento, que representan la revoltura, el desorden y el caos.

En este sentido, existe un viaje de la naturaleza a lo sintético, una performatividad del paisaje funerario en la manera en que las flores plásticas por su sustrato material se masifican, expandiendo 'lo homogéneo' en estos lugares de construcción subjetiva y particulares como son los cementerios, creando nuevas relaciones socioespaciales desechables por los volúmenes de su producción e imperecederas por su materialidad, creando este juego dual finito-perenne. Asimismo, se cumple con los ritos tradicionales que tienen premisas preestablecidas sujetas al culto local en comunión con procesos de globalización y la producción de plástico, símbolo de la modernidad. En otras palabras: ya no hay tiempo para la visita dominical al cementerio. La ofrenda floral deja de ser un ritual de cada semana y pasa a ser un adorno perpetuo del espacio físico "habitado" por el fallecido y construido por el visitante que propaga lo igual en el paisaje.

No obstante, que este rito haya perdido en parte su sentido tradicional y se haya mercantilizado, no implica que estén vacías de sentido. Lo esencial es la memoria y lo perdurable en el tiempo. Por ello, -y mientras tanto-, las flores desamparadas en Balmaceda subsistirán aquietadas en el tiempo a la espera de la próxima visita, al asecho de los caprichos del viento o simplemente permanecerán lo que dura el plástico y sin desvanecerse terminarán desahuciadas en algún basural, esperando mil años para morir. 


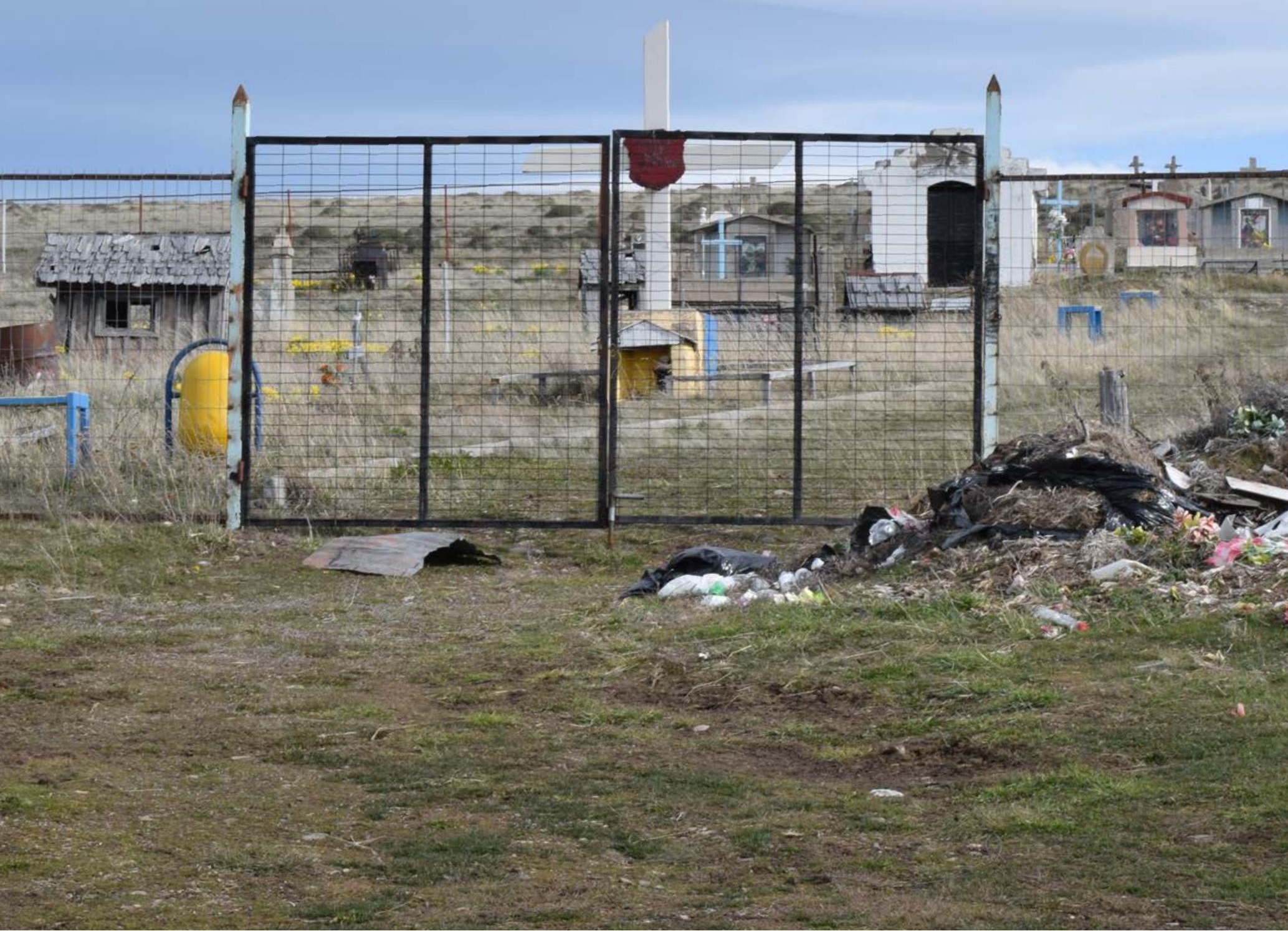




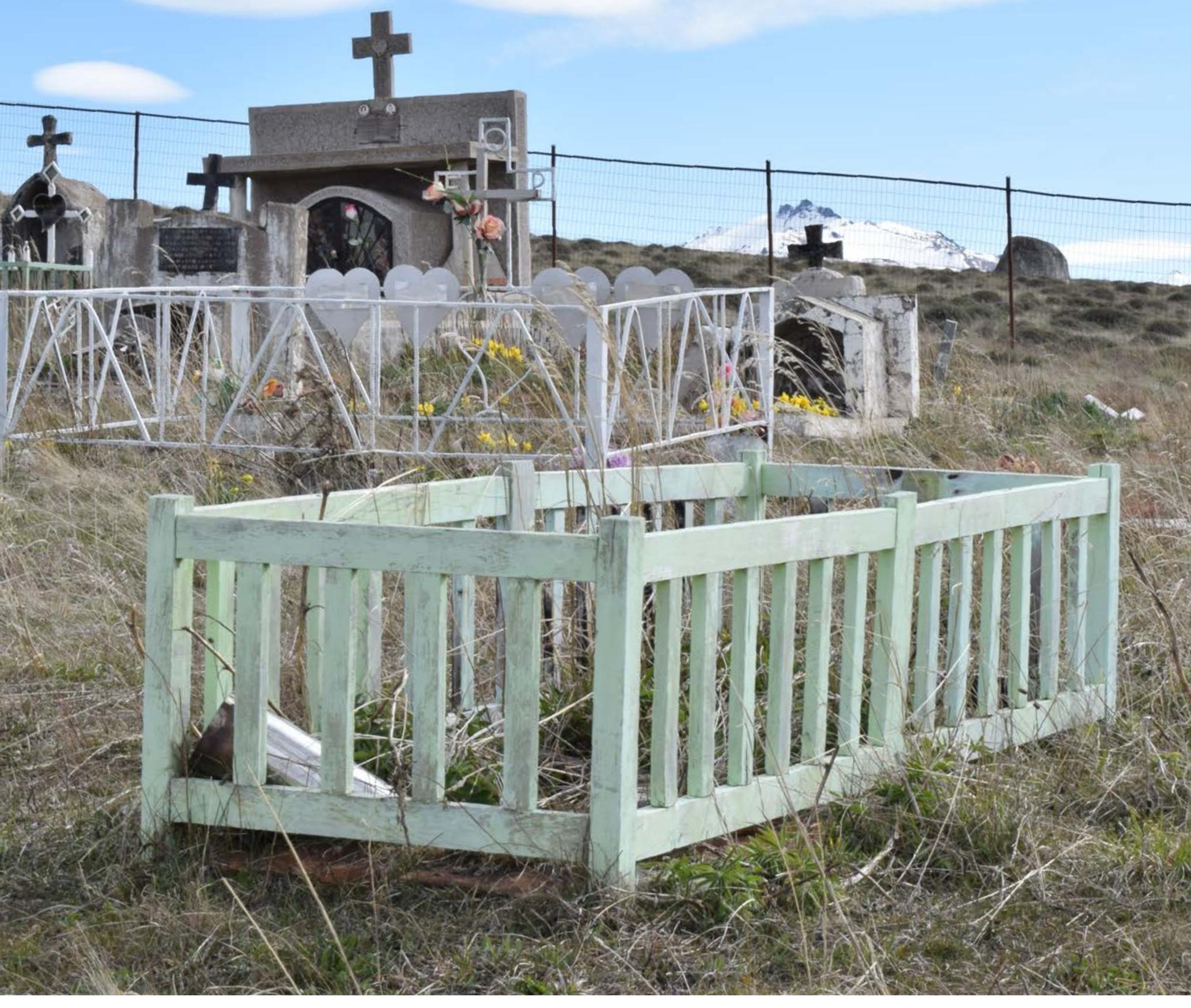




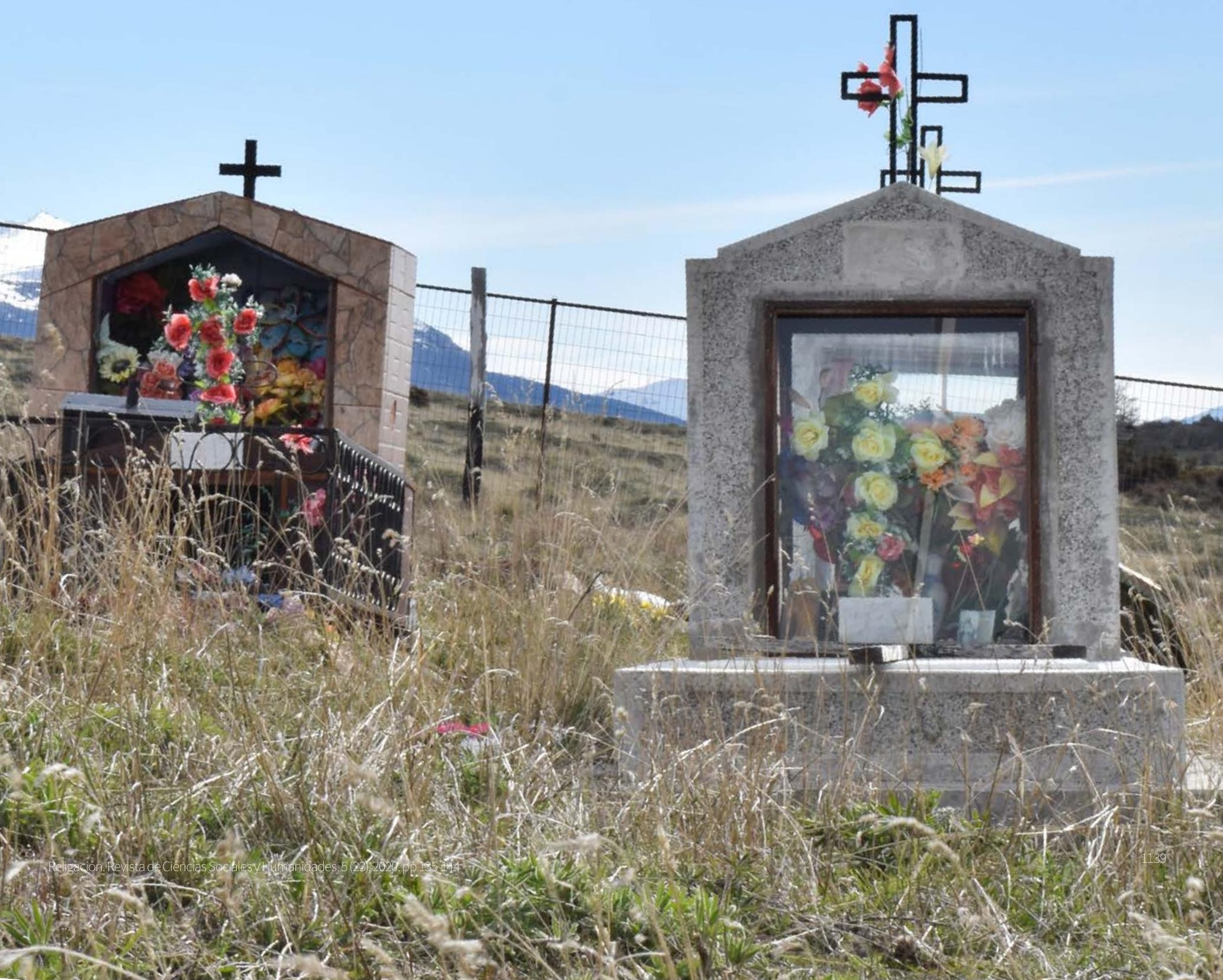


RENDICIÓN

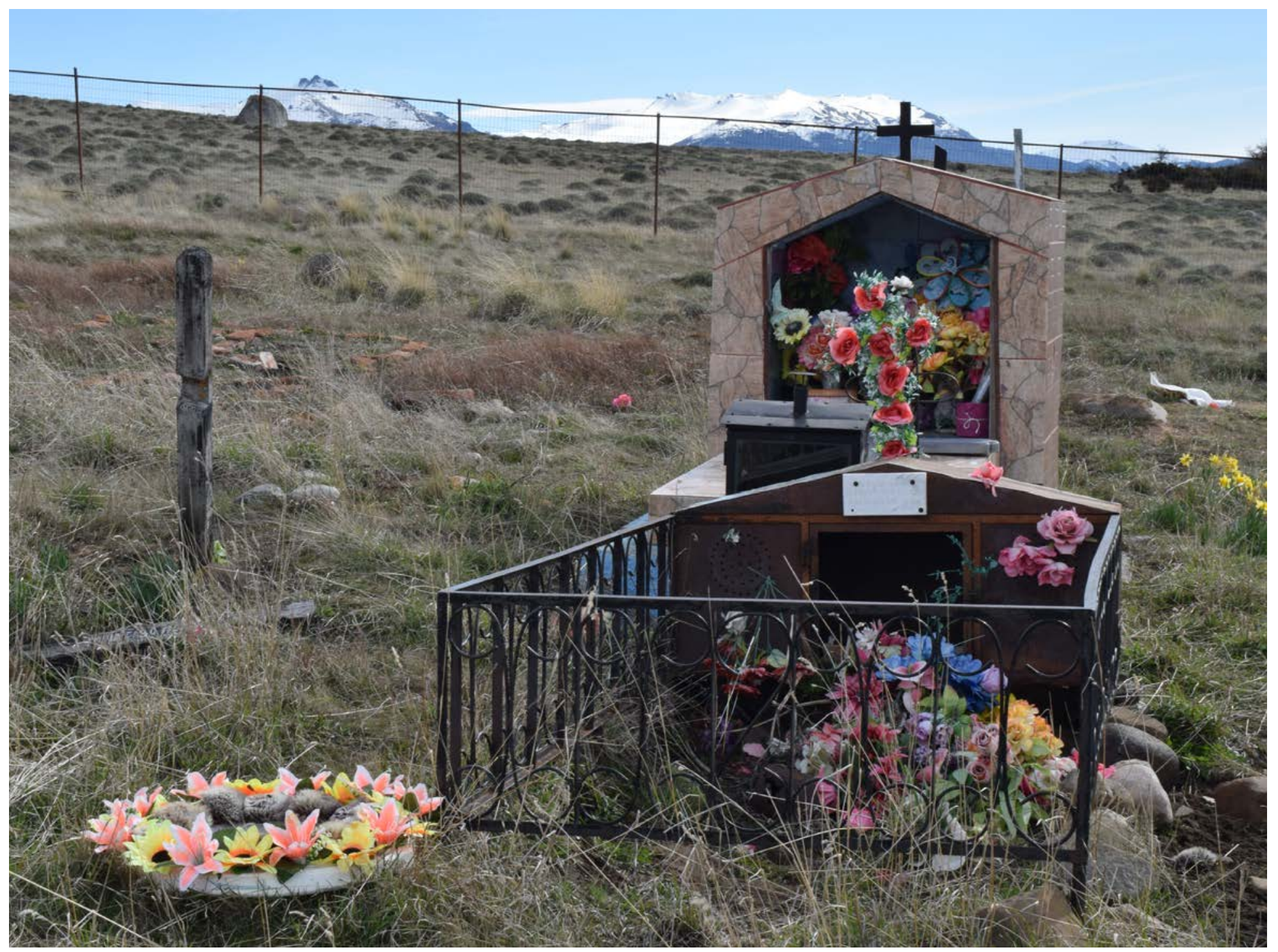




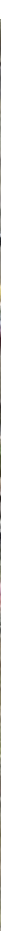

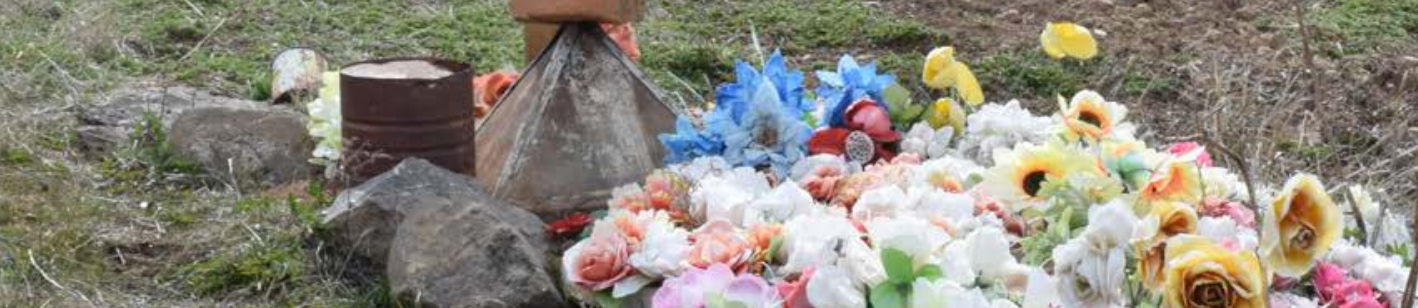

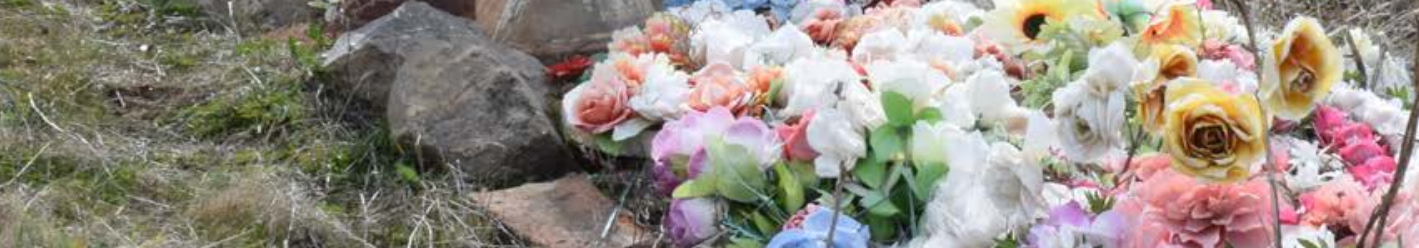

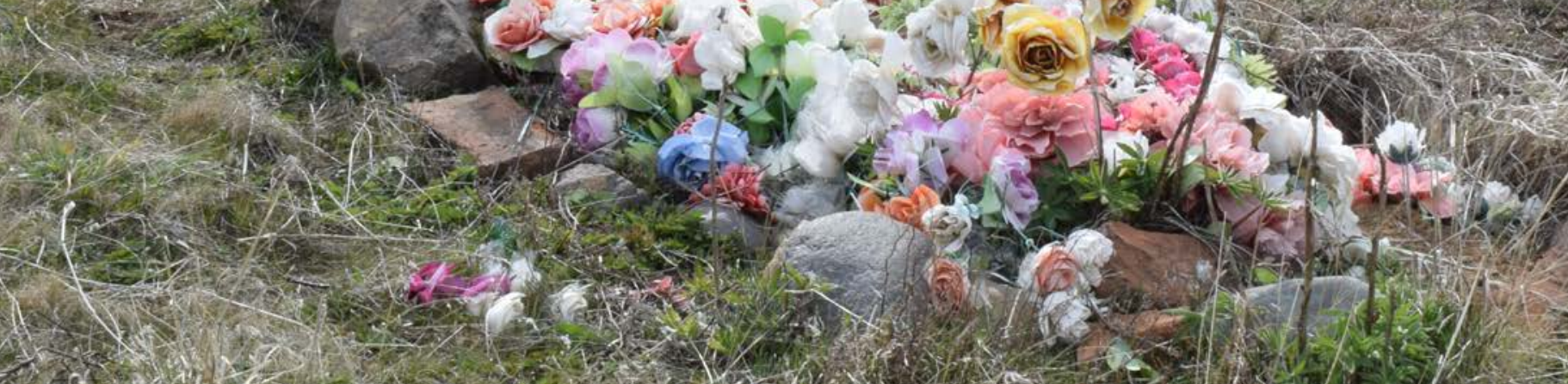

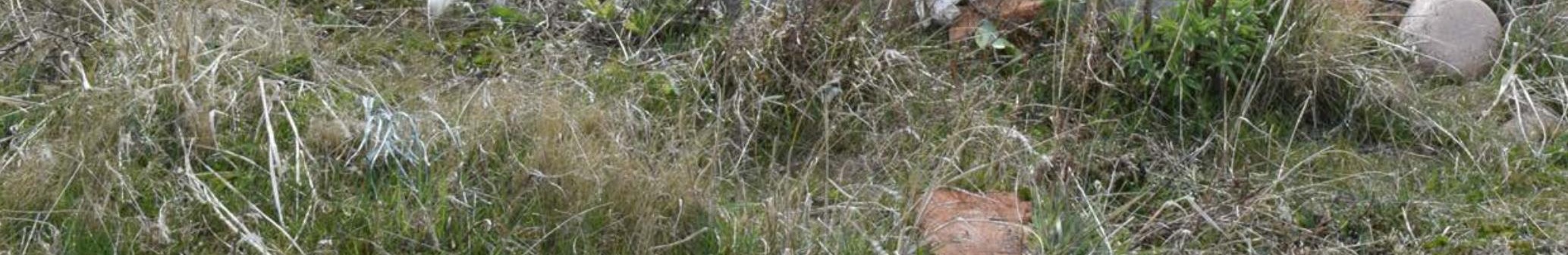

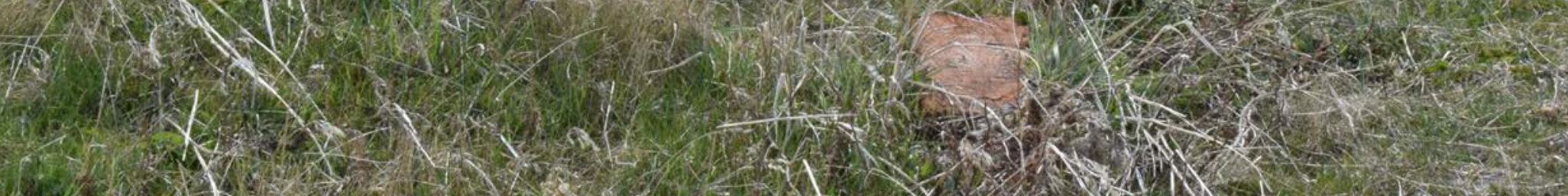

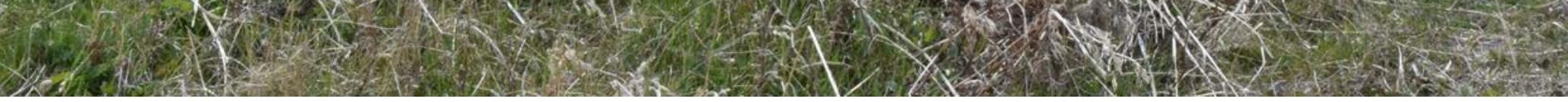




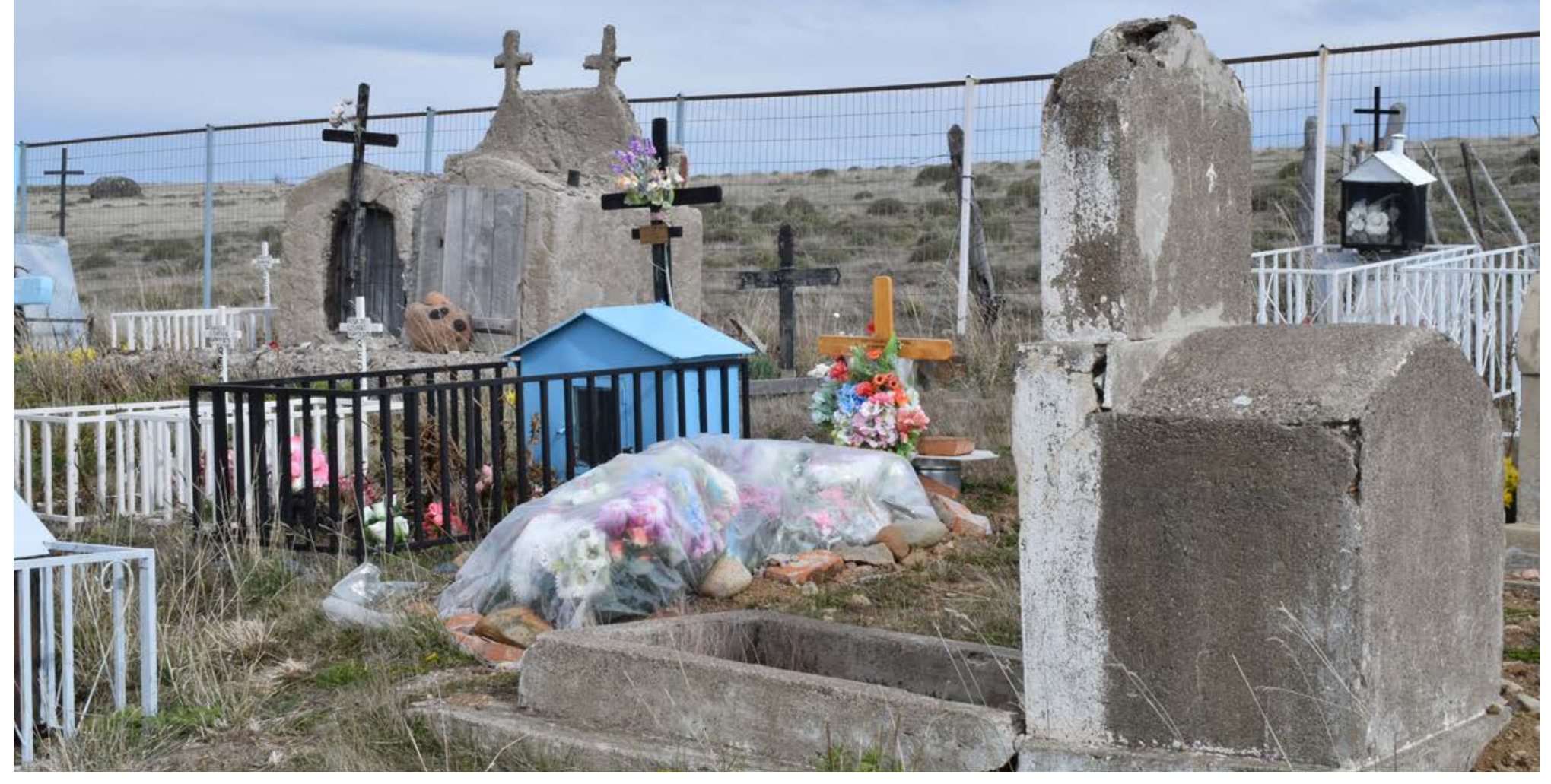

RITO

PASAJE

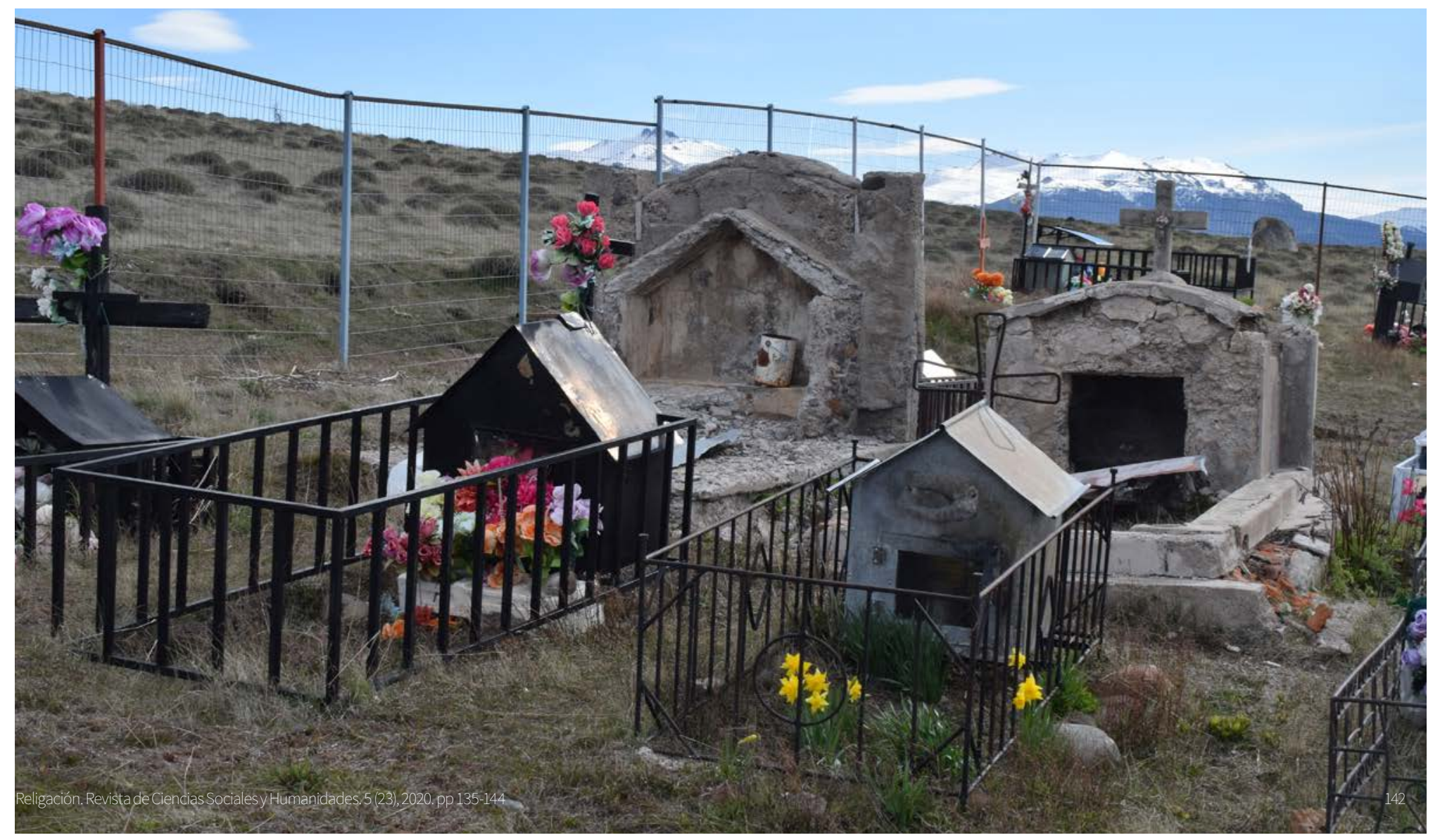




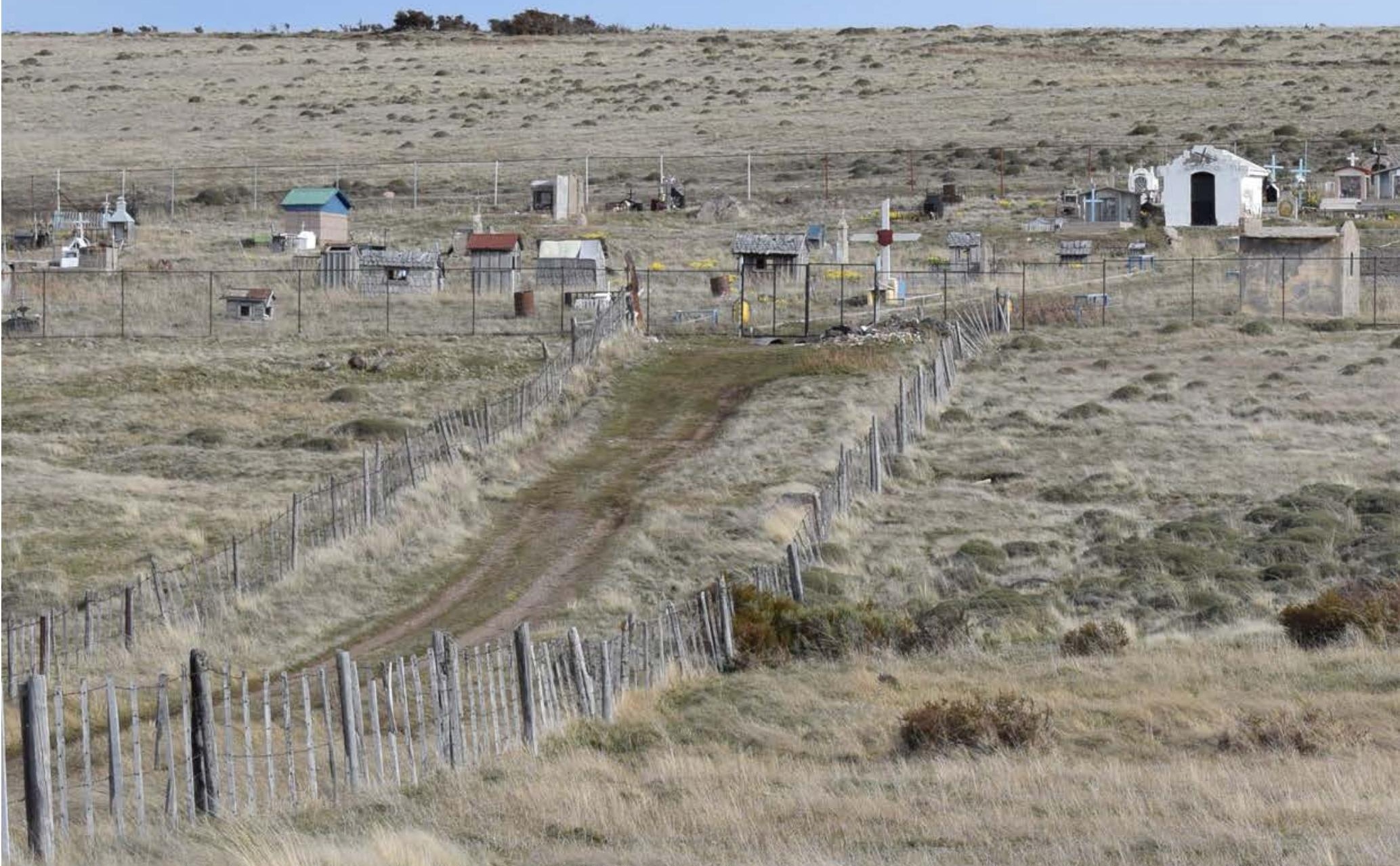

How to cite this article: Rodríguez Moraga, C. (2020). Paisaje fúnebre, Desvanecimiento del rito de ofrenda y proliferación. de lo igual. Religación. Revista De Ciencias Sóciales YHumanidades, 5(23), 135-144. Recuperado a partir de http://revista. rêligacion.com/index.php/religacion/article/view/607

Sulomitted: 15 August 2019 Accepted:04 March 2020 Published: 31 March $2020 \ldots$

Mit. (1) 